\title{
Characteristics of Effective Classroom Teachers as Identified by Students and Professionals: A Qualitative Study
}

\author{
Leila Jahangiri, D.M.D., M.M.Sc.; Thomas W. Mucciolo, B.B.A. \\ Abstract: This qualitative research study identified criteria for teacher quality preferences as perceived by current and past stu- \\ dents. A two-question, open-ended survey asking what qualities learners liked most and least in a teacher/presenter was given to \\ two groups: students (Group A) from medicine, dentistry, and related residency programs; and dentists and physicians (Group B) \\ who had graduated at least three years previously and who attended a minimum of two days of continuing education courses in \\ lecture format each year. A total of 300 subjects provided 2,295 written responses. Descriptive words within the responses were \\ coded and grouped according to similar relationships, resulting in the emergence of twenty-one defined categories that were fur- \\ ther refined into three core categories: personality, process, and performance. Results showed that the two groups appear to have \\ different preferences in teacher/presenter characteristics. For Group A (students), the categories of content design, content orga- \\ nization, and content development were at the forefront of their preferences. Group B (professionals) overwhelmingly favored \\ elements of speaker self-confidence and expertise. Both groups highly valued expertise and speaking style. These findings can be \\ used to develop curriculum, enhance faculty members' teaching skills, and plan continuing education programs.
}

Dr. Jahangiri is Assistant Professor and Chair, Department of Prosthodontics, New York University College of Dentistry; and Mr. Mucciolo is Adjunct Assistant Professor, Department of Prosthodontics, New York University College of Dentistry, as well as President of MediaNet, Inc. and author of several books on presentation skills. Direct correspondence and requests for reprints to Dr. Leila Jahangiri, Department of Prosthodontics, College of Dentistry, New York University, 423 East $23^{\text {rd }}$ Street, 16 North, New York, NY 10010-4086; 212-998-9279 phone; 212-995-4686 fax; 1j14@nyu.edu.

Key words: teaching effectiveness, teacher characteristics, teaching preferences, effective teachers, teaching assessment, qualitative research

Submitted for publication 10/24/07; accepted 1/30/08

$\mathrm{T}$ Teaching evaluation is a necessary process in any educational setting. There are a number of tools or instruments available that are used to assess the level of effectiveness of instructors. ${ }^{1}$ These mechanisms can be categorized into three major areas: student ratings, peer reviews, and self-evaluations. The most often used measurement has been the student rating of instruction or student evaluation, as it is more commonly known. Students' rating of instruction has been a highly debated subject, ${ }^{2-20}$ but it is generally believed that student evaluations are reliable and often one of the best methods for obtaining measurements of the quality of classroom instruction. Thus, it is not surprising that, for the past three decades, student evaluation - typically involving a rating scale that addresses various dimensions of the instructional process and presentation style - has been the primary strategy used for measuring the effectiveness of teaching that occurs in classroombased courses. ${ }^{21}$

Evaluations can be used for formative and summative purposes as originally proposed and described by Scriven. ${ }^{22}$ Formative evaluations of teaching are used to review, train, and improve existing faculty. Summative evaluations are used to make decisions about promotions, tenure, awards, or merit pay increases. ${ }^{23}$ Whereas formative results are designed to improve the teaching process as a continuous feedback mechanism, summative results can be a determinant of a faculty member's progress to achieving his or her goal.

The educational literature describes desirable and undesirable teacher attributes that affect classroom teaching. ${ }^{9,24-31}$ These attributes include personality traits, instructional organization, and the instructor's ability to make the subject useful. Studies of both faculty members' and students' perceptions of effective teachers and effective teaching yielded characteristics that included the following: caring, encouraging, approachable, enthusiastic, respectful, knowledgeable, empathetic, passionate, and having a sense of humor. ${ }^{27,31,32} \mathrm{~A}$ teacher who develops a clearly defined, well-organized topic is typically considered to be helpful in the learning process. ${ }^{25,33-37} \mathrm{An}$ energetic instructor who can simplify complex topics, while appearing completely in control of the class, is perceived to be more effective than instructors who do not exhibit these characteristics..$^{25,35,36,38-42} \mathrm{An}$ 
educator who is easily understood, stays focused on the learning objectives, and interacts directly with the students is perceived to create a better environment for the retention of knowledge than instructors who do not. ${ }^{25,34-36,41,43-45}$

One of the more notable definitions of teaching effectiveness was expressed by Derek Bok, former president of Harvard University: "The willingness to continue teaching must always rest upon an act of faith that students will retain a useful conceptual framework, a helpful approach to the subject, a valuable method of analysis, or some other intangible residue of lasting intellectual value." ${ }^{46}$ Thus, teaching effectiveness can be defined as the ability to be useful, helpful, and valuable in facilitating learning. In summary, the effective teacher is one who contributes to a student's acquisition of knowledge and skill by using a number of techniques associated with the promotion of learning and who displays personal characteristics commonly associated with a positive learning environment. ${ }^{23,47}$

Studies indicate that preferred teacher characteristics, as perceived by students, are related to the assessment of teaching effectiveness..$^{24,25,30,35,48,49}$ For example, a study on personality types of beginning health occupations education teachers noted eighteen competencies relating to teaching effectiveness. ${ }^{35}$ When analyzing the competency statements, fifteen of the eighteen competencies found in teachers were similar to fourteen of the preferred teacher characteristics identified in our study. Because the measurement of teaching effectiveness is, in part, derived from student perceptions, the research suggests that institutions relying on students' ratings of instruction as a tool for measuring teaching effectiveness should consider designing the teacher evaluation form based on current student preferences of teacher characteristics. ${ }^{25}$

In spite of the wealth of information on the value of student evaluation, one of the recognized difficulties in designing a student evaluation is to decide what should be evaluated.$^{50}$ If an open-ended question format is used, then the student provides the criteria for evaluation. If an objective-based format is used, then the institution predetermines the criteria from which the student must choose. Regardless of the format, the design of the evaluation should help develop better faculty, courses, and departmental/ institutional goals for teaching.

The purpose of this study was to identify, through a qualitative methodology, preferences for teacher/presenter qualities as perceived by students.
Since preferences may be different for current students as compared to past students, two groups were studied: students in the fields of medicine, dentistry, and related graduate residency programs, and professionals in the same fields who had completed their education at least three years previously. In this qualitative research study, open-ended questions unrelated to any specific instructor, training course, or exam were used for students to evaluate teachers in a classroom or equivalent setting, such as a seminar, conference, group presentation, or continuing education course.

The outcome of assessments of classroom teaching preferences can have utility for designing and implementing dental school instruction and for planning continuing education programs.

\section{Methods}

Qualitative research involves collecting descriptions of events as compared to collecting data elements that can take numerical form; the method thus involves analyses that are nonquantitative. ${ }^{51}$ Whereas quantitative research involves concepts of reliability and validity of data, qualitative methodology is explained by such words as "exploration, meaning, thematic, and understanding." 52 Qualitative data involve words; quantitative data involve numbers. However, numerical data can be extracted or can be useful in summarizing the results of a qualitative analysis.

Qualitative data collection methods often include open-ended interviews, direct observation, and written documents such as open-ended questionnaires. In our study, the data-gathering was identified as a phenomenology type of qualitative research in which a collected body of knowledge relates several different observations of phenomena to each other. ${ }^{53}$ The data-gathering method was chosen to be a written document in the form of an open-ended questionnaire because open-ended, face-to-face interviews carry the potential of the subject feeling pressured, intimidated, or in some way stressed due to the presence of the interviewer. In addition, the time investment required of subjects participating in open-ended interviews was considered to be prohibitive in the conduct of this study.

Unlike quantitative researchers, qualitative researchers cannot determine how many participants are necessary prior to the study. In qualitative research, data analysis is performed simultaneously 
as data is collected until a saturation occurrence emerges. ${ }^{54}$ At this point, the more data that are gathered, the less each additional data point appears different from the previously collected data. Saturation is considered the end point of collecting data. The ultimate purpose of a qualitative type of assessment is to make conclusions that are transferable, using a vast collection of information. ${ }^{55}$

In this study, subjects over the age of twentyone were asked to volunteer for participation. The study, conducted from June 2006 to June 2007, was approved by the New York University Institutional Review Board and categorized as an exempted research protocol. Participants were divided into two groups. Group A subjects consisted of students and residents from medicine, dentistry, and related residency programs. Group B subjects consisted of dentists and physicians who had graduated at least three years previously and who had attended a minimum of two days of continuing education courses in lecture format each year since the completion of their professional training. The purpose of assessing the opinions of individuals in both groups was to identify perceptions of teaching effectiveness from the perspectives of current students and practicing professionals.

An open-ended survey was given to the volunteer research participants. For Group A participants, a one time computer survey link was sent electronically by email to a random sample of New York University medical and dental students and residents from all years of their education. For Group B (medical and dental professionals), a sample of participants who attended continuing education courses was randomly selected and asked to participate in a one-time electronic survey. The survey was conducted in the same format as was done for Group A, except that a different electronic link was provided in the emails to Group B participants so as to allow for a separation of the two groups when the surveys were returned. Group B subjects (professional practitioners) had previously agreed to be contacted by email. Neither groups' surveys were connected to any specific course offerings, nor were the surveys completed in the presence of an instructor.

For both groups, the survey asked two questions: with regard to classroom teaching, 1) what qualities do you like MOST in a teacher/presenter? and 2) what qualities do you like LEAST in a teacher/presenter? The subjects were allowed to provide multiple responses to each of the questions in a typewritten electronic form with no limit on the length of any response. Subject enrollment in the study continued until data saturation was achieved at 300 subjects. The data collections for Group A and Group B were separated by the two different survey links provided in the emails to each group. The responses were anonymous and contained no other information to identify the subjects or subgroups (medical or dental) in any way.

\section{Results}

Data saturation was achieved with 300 subjects: 156 from Group A and 144 from Group B. The 300 subjects provided 2,295 responses: 981 from Group A (students) and 1,314 from Group B (professionals). The mean numbers of responses were 6.3 for Group A subjects and 9.1 for Group B subjects.

\section{Key Word Analysis}

The use of the open-ended survey questions resulted in the collection of 2,295 responses that were sorted according to similarities. For the purposes of this study, a "response" was defined as a word, phrase, or sentence that contained at least one key word that described effective or ineffective teacher characteristics or behaviors. The educational literature describes methods for narrowing down a large collection of data elements into manageable sections or clusters that are grouped and organized by conditional relationships ${ }^{56}$ and then categorized..$^{54,56-65}$ The process used in this study was a constant comparison method of identifying, coding, and categorizing the primary patterns in the data, leading to defined categories and core categories that emerged from the data. ${ }^{54,56,58,60,61,64,65}$

The first task in sorting the 2,295 responses in this study involved analytic coding ${ }^{57}$ to identify, on a line-by-line basis, descriptive words within the responses and then group the descriptive words according to similar relationships. For instance, one response read, "I like when the teacher is considerate of my opinions." Another response read, "Cares about what I say." And another response read, "The best teachers are helpful, supportive, and thoughtful." The descriptive words in those three examples include "considerate, cares, helpful, supportive, and thoughtful," and these words were considered to be similar in relationship. Some responses included a combination of descriptive words that were dissimilar. For example, one response read, "I like instructors who ask good questions and respect my time by fin- 
ishing on time and not rushing through the material." The descriptive phrases in that response were "ask good questions," "respect my time," and "not rushing through the material." These three phrases were not considered similar in relationship, and they were categorized into three different groups.

The second step in the analysis was to examine the descriptive word groupings to see which words were used more frequently in order to identify meaningful patterns ${ }^{62,65}$ or repetitive combinations that emerged out of the data. ${ }^{59,65}$ Words used several times in similar contexts across multiple responses were considered to be more common and were highlighted as specific key words (Table 1). For example, the word "considerate" appeared in only one response, but the word "helpful" appeared in several responses, thus making it a key word for the purposes of this study.

Because the survey questions asked subjects to identify "likes" and "dislikes," responses were both positive and negative. The review of the responses led to identification of positive and negative key words and phrases found within each response. However, negative formats of certain words were considered similar and mentioned only as positive or negative, but not both. For example, a number of responses included the word "helpful," and one response included the phrase "not very helpful." The positive version ("helpful") was retained as the key word. Yet, in some cases, opposites were mentioned multiple times, and both the positive and negative versions were retained as key words. An example of this was found with the words "understanding" and "lack of understanding," each of which appeared in multiple responses.

\section{Checks and Balances for Data Dependability}

When categorizing seemingly related data bits into distinct groupings, studies suggest establishing a consistency using some set of rules or guidelines for organizing the data. ${ }^{66}$ The established rules should allow for data to be examined and re-examined by different observers, independently, and yield relatively similar results when categorizing the data. ${ }^{62}$ To ensure such data integrity and interrater reliability ${ }^{25,67}$ in this study, two researchers independently analyzed the responses, identifying descriptive words and grouping them by similarity. Any discrepancies or uncertainties were discussed by the two researchers to arrive at the most logical assignment of a descriptive word to a particular group, based on the context in which the response was written. ${ }^{25}$
For example, one response read, "I don't like it when the teacher puts me down in front of the class when I ask a question." The phrase "puts me down in front of the class" could be grouped with words like "disrespect" and "lack of understanding," or the phrase could be grouped with words like "sarcastic" or "has an attitude." The researchers discussed the ambiguity and agreed on how to best group the response. In this case, the response fit better into the group of words that included "disrespect." During the independent analysis of the 2,295 responses, less than 3 percent of the descriptive words were assigned to different groupings by each researcher. This minimal amount of difference in the interpretation of the results and the ability to resolve each difference through open discussion enhanced the dependability of the qualitative research..$^{52,68}$

\section{Defined Categories}

The descriptive words and phrases found in the responses were assigned to similar groups, and then the more commonly used words in each group were highlighted as positive and negative key words. Using inductive analysis ${ }^{65}$ and continual refinement ${ }^{62}$ of the key words, twenty-one categories emerged, which were defined (labeled) and validated according to specific references found in the existing educational literature (Table 1). For example, the key word "helpful" was assigned to a category that, through refinement, was ultimately defined as "caring." The defined categories emerged from the data (key words) rather than predetermining the categories to fit the data. ${ }^{64,65}$

Once the defined categories emerged, more precisely worded descriptions were created to distinguish one category from another. ${ }^{62}$ The descriptions for the twenty-one defined categories in this study, together with their related key words, are shown in Table 1. As an example, the defined category of "caring" was described as "viewed by the student as genuine and sincere." One category, "inspiration," had only positive key words but no negative key words.

\section{Core Categories}

Qualitative analysis methodology stipulates that where a number of independent categories of data exist, several categories can be grouped or clustered into one or more core categories to further refine the data into related phenomena. ${ }^{57}$ The core categories become major themes from which theory can be expressed. ${ }^{25,52,57,60}$ 
Table 1. The twenty-one defined categories, related definitions, and associated positive and negative key words assigned to each category

Defined Category and Definition

1. Caring $25,27,30,31,35,39,40$

Viewed by the student as genuine and sincere.

\section{Empathy $9,25,27,28,31,35,36,40$}

Sees and understands from the perspective of the student.

3. Happiness $9,31,32,41,42$

Evidently enjoys giving the presentation.

4. Energy $25,36,39,42$

Demonstrates liveliness in sharing knowledge.

5. Passion ${ }^{25,31}$

Believes in what he or she is presenting.

6. Motivation $24,25,27,29,31,35,36,40$

Instills a sense of enthusiasm.

7. Expertise $25,27,30,31,35,39,40$

Logically explains or simplifies the materials.

8. Inspiration $9,24,25,31,35$

Student feels encouraged to incorporate learned concepts.

9. Self-Confidence ${ }^{25,39-42}$

Appears prepared and in control of the presentation or discussion, regardless of the audience size, level of expertise, or rank.

10. Approachable $9,25,27,31,35,36,39-41,44$

Appears friendly and receptive to comments and interaction.

11. Personal Appearance 25,40 Looks and behaves professionally.

12. Content Organization $9,24,25,29,31,35,36$ Applies concepts using real-world situations to simplify content.

13. Content Development $t^{9,25,28,34-37}$

Develops a clear and concise message.

14. Content Design $33,34,36,37,45$

Creates support visuals that enhance the teaching without detracting from the lecture.

15. Additional Sense Stimulation $35,41,45$ Appeals to multiple senses at the same time.

16. Environment ${ }^{25,34,35,41}$

Creates favorable conditions for presenting content.

17. Body Language Style $25,29,36,38,40-44$

Uses physical movements and gestures to support the presentation.

18. Speaking Style $25,28-30,35,36,41,44$

Can be easily heard and understood while using proper inflection and tone when speaking.

19. Technology 34,36,37,45

Demonstrates familiarity with all equipment and other technical elements (such as multimedia).

\section{Focus $25,35,36$}

Generates recurring references to major points.

21. Interaction ${ }^{25,34-36,44,45}$

Establishes a connection with the students/ audience through questions, comments, and other participation
Positive Key Words

caring, encouraging, helpful

empathy, understanding, feelings, personal experience

smiles, humor, fun, entertaining

energetic, engaging, attentive, engrossing, excited, dynamic, spirited passionate, likes the subject, from the heart, credible

motivating, moving, good feeling, energizing, enthusiastic

knowledgeable, simplifies, relates to the audience, command of material

want to learn more, stimulated, relevant, take-home value

calm, control, self-confident, prepared, practiced, can think on their feet

encourages participation, allows questions, friendly

polished, professional

good construction, well thought-out, provides references, uses examples

clarity, elaborates, tells stories, uses cases

good slides, good PowerPoint, uses pictures to explain topic

multimedia, animation, hands-on

starts on time, comfortable seating, good view of presenter and screen relaxed, poise, good posture, makes eye contact

easy to listen to, pauses, speaking style, clear speech

handles glitches

key issues, main ideas, sticks to topic

handles tough questions, involves, repeats responses, asks good questions
Negative Key Words

attitude, critical, arrogant, sarcastic, gives negative comments

lack of understanding, single viewpoint, no sympathy, disrespect

anger, disappointment

looks too serious, tired, deadbeat

apologizes for the topic, appears to dislike the topic boring, dull, uninteresting

complex, too thorough, lightweight

(no key words given)

nervous, anxious, intimidated, afraid of questions

interrupts student, never asks, discourages questions

sloppy, inappropriate

confusing ideas, disorganized, abstract references

rushes through material, too many points, too much material cluttered slides, too much animation, not readable, long sentences, paragraphs of text, words not visible on background, slides not related to topic

poor sound quality

too dark, room too cold, people walking in and out

points to people, moving around, shifting, turns away, never moves

talks too fast, mumbles, says "um," monotonous, soft voice, reads slides

laser pointer movement, standing in front of screen, intimidated with technology, technical problems

drifts from topic, off tangent

picks on people, ignores suggestions 
Once the core categories emerged as major themes, a data verification check was done to make certain that all twenty-one defined categories were linked to one of the three core categories and, moreover, that all 2,195 responses were accounted for and linked to one of the twenty-one defined categories. As such, each original response was associated with a defined category and a core category. ${ }^{25}$

In this study, a review of the twenty-one defined categories led to three core categories: personality, process, and performance (Table 2). The "personality" traits of the teacher/presenter represented eleven categories that focused on individual behavior irrespective of course content or delivery of that content. The "process" was related to five categories dealing with the organization and design of the content that is used for instructional purposes. The "performance" involved five categories related to the presentation skills inherent in the delivery of the content.

Tables 3 and 4 show the results of the twentyone defined categories for Group A (Table 3) and Group B (Table 4) by reporting the number of people responding as well as number of key word responses. The results are presented in the order of the number of people responding. For example, in Table 3, the defined category of "content design" shows that ninety-three of the 156 subjects (59.6 percent) of Group A reported "content design" as a factor in what they liked or disliked about a teacher/presenter. The reason that the total percentages for the "number of people responding" exceeds 100 percent across all twenty-one defined categories is because each subject provided multiple responses.

For ease of understanding, an analysis of the "number of key word responses" was also tabulated for the corresponding categories. Every key word response was mapped to a specific defined category. Thus, for Group A (Table 3), 10.4 percent of the key word responses were assigned to the "content design" category. For "key word responses," percentages in all twenty-one defined categories totaled 100 percent.

Students in Group A (Table 3) indicated that the most important categories (over 50 percent of the responding students) were content design, content organization, content development, expertise, and speaking style. The professional subjects in Group B (Table 4) indicated that the most important categories (over 50 percent of the responding practitioners) were self-confidence, expertise, speaking style, and energy. The categories of expertise and speaking style were considered important by both groups.

Based on the number of subjects responding, the greatest disparity between the groups occurred with the category of self-confidence. Seventy-five percent of the dentists and physicians in Group B considered this as the most significant category as compared to 19.2 percent of the students in Group A.

When key word responses were clustered into the core categories of personality, process, and performance (Tables 2 and 5), differences appeared between Group A and Group B. Although both groups considered personality as the most significant of the three core categories, Group B gave greater weight (59.51 percent) to that category than did Group A (38.23 percent). Conversely, Group B gave less weight to process (11.80 percent) than did Group A (37.0 percent). Perceptions of the performance core category were similar for both groups (24.77 percent for Group A and 28.69 percent for Group B).

\section{Discussion}

What makes this study different from others is that these findings compare current students and residents with professional practitioners. The majority of the literature, as described in this report, focuses on the perceptions of students who have not completed their 
Table 3. Medical and dental students' (Group A) preferences, listed by defined category, in order of people responding Defined Category

$$
\text { People Responding }
$$

\begin{tabular}{lcccc} 
& & & & $(\mathrm{n}=981)$ \\
& Number & Percent & Number & $156)$ \\
\hline Content Design & 93 & $59.6 \%$ & 102 & $10.4 \%$ \\
Content Organization & 84 & $53.8 \%$ & 117 & $11.0 \%$ \\
Content Development & 81 & $51.9 \%$ & 108 & $11.0 \%$ \\
Expertise & 81 & $51.9 \%$ & 117 & $11.9 \%$ \\
Speaking Style & 78 & $50.0 \%$ & 60 & $6.1 \%$ \\
Interaction & 54 & $34.6 \%$ & 48 & $4.9 \%$ \\
Caring & 45 & $28.8 \%$ & 39 & $4.0 \%$ \\
Focus & 39 & $25.0 \%$ & 39 & $4.0 \%$ \\
Empathy & 36 & $23.1 \%$ & 42 & $4.3 \%$ \\
Approachable & 33 & $21.2 \%$ & 33 & $3.4 \%$ \\
Energy & 30 & $19.2 \%$ & 33 & $3.4 \%$ \\
Self-Confidence & 30 & $19.2 \%$ & 21 & $2.1 \%$ \\
Happiness & 18 & $11.5 \%$ & 21 & $2.1 \%$ \\
Motivation & 15 & $9.6 \%$ & 21 & $2.1 \%$ \\
Additional Sense Stimulation & 15 & $9.6 \%$ & 21 & $2.1 \%$ \\
Body Language Style & 15 & $9.6 \%$ & 15 & $1.5 \%$ \\
Personal Appearance & 15 & $9.6 \%$ & 15 & $1.5 \%$ \\
Environment & 15 & $9.6 \%$ & 9 & $0.9 \%$ \\
Inspiration & 9 & $5.8 \%$ & 6 & $0.6 \%$ \\
Passion & 6 & $3.8 \%$ & 981 & $0.6 \%$ \\
Technology & 6 & $3.8 \%$ & & $100 \%$ \\
Total Responses & & & &
\end{tabular}

Table 4. Medical and dental professionals' (Group B) preferences, listed by defined category, in order of people responding

\begin{tabular}{|c|c|c|c|c|}
\hline \multirow[t]{2}{*}{ Defined Category } & \multicolumn{2}{|c|}{$\begin{array}{c}\text { People Responding } \\
(\mathrm{n}=144)\end{array}$} & \multicolumn{2}{|c|}{$\begin{array}{l}\text { Key Word Responses } \\
\qquad(n=1314)\end{array}$} \\
\hline & Number & Percent & Number & Percent \\
\hline Self-Confidence & 108 & $75.0 \%$ & 195 & $14.8 \%$ \\
\hline Expertise & 105 & $72.9 \%$ & 186 & $14.2 \%$ \\
\hline Speaking Style & 80 & $55.6 \%$ & 144 & $11.0 \%$ \\
\hline Energy & 73 & $50.7 \%$ & 95 & $7.2 \%$ \\
\hline Body Language Style & 61 & $42.4 \%$ & 94 & $7.2 \%$ \\
\hline Content Development & 54 & $37.5 \%$ & 71 & $5.4 \%$ \\
\hline Approachable & 52 & $36.1 \%$ & 71 & $5.4 \%$ \\
\hline Focus & 52 & $36.1 \%$ & 64 & $4.9 \%$ \\
\hline Empathy & 47 & $32.6 \%$ & 62 & $4.7 \%$ \\
\hline Happiness & 42 & $29.2 \%$ & 55 & $4.2 \%$ \\
\hline Interaction & 41 & $28.5 \%$ & 54 & $4.1 \%$ \\
\hline Content Organization & 39 & $27.1 \%$ & 50 & $3.8 \%$ \\
\hline Inspiration & 26 & $18.1 \%$ & 29 & $2.2 \%$ \\
\hline Caring & 24 & $16.7 \%$ & 26 & $2.0 \%$ \\
\hline Passion & 23 & $16.0 \%$ & 27 & $2.1 \%$ \\
\hline Content Design & 22 & $15.3 \%$ & 23 & $1.8 \%$ \\
\hline Motivation & 20 & $13.9 \%$ & 25 & $1.9 \%$ \\
\hline Technology & 17 & $11.8 \%$ & 21 & $1.6 \%$ \\
\hline Personal Appearance & 10 & $6.9 \%$ & 11 & $0.8 \%$ \\
\hline Environment & 5 & $3.5 \%$ & 8 & $0.6 \%$ \\
\hline Additional Sense Stimulation & 3 & $2.1 \%$ & 3 & $0.2 \%$ \\
\hline Total Responses & & & 1,314 & $100 \%$ \\
\hline
\end{tabular}


education, as well as on teachers' personality types or behaviors. There appears to be a scarcity of similar investigations that compare students with professionals, making these findings unique in that respect.

These findings can be used to develop curriculum, design faculty enrichment programs, and plan continuing education programs. Results from the responses of dental and medical students and residents (Group A) indicate that these individuals most valued the content categories consisting of design, organization, and development. It is apparent that the main concern of this group is in the understanding of information. This is an expected outcome from students who are often tested on materials presented. Efforts in developing faculty who teach this group should concentrate on content design, content organization, and content development as a priority. Because clarity of content is of the highest value to students, other effective educational delivery methods beyond the classroom can be considered such as electronic/web-based courses. In this manner, curriculum and courses can be enhanced by concentrating on faculty development.

Unlike the students, professionals taking continuing education courses appear to value content to a lesser degree. Instead, this group places significance on the self-confidence and expertise of the teacher as important mechanisms to enhance their learning. Whereas self-confidence relates to the "impression" made by the teacher, expertise is associated with the "expression" of information. Expertise is defined here as the ability to "logically explain and simplify content" (Table 1). Since professionals use continuing education to add to existing knowledge, it may be that the extra time they invest in the learning (beyond the workday) carries a greater sense of urgency. It is reasonable to speculate that professionals may demand that the teacher transfer knowledge more quickly and explain concepts more simply. Both groups (A and B) gave significance to the category of expertise. This is likely because they each require a teacher who can simplify complex topics.

Speaking style, a performance-related category, was notably important to each group. Both groups value the clarity of verbal communication in the learning process. In developing faculty, it appears that any efforts made to enhance the speaking style of a teacher would benefit the student from a learning perspective.

Body language, which creates a more physical and visible impression, was rated highly by professionals but not very highly by students. This is evi-
Table 5. Percent of key word responses by group, listed by core category

Core Category Percent of Key Word Responses

\begin{tabular}{lcc}
\hline & $\begin{array}{c}\text { Group A } \\
(\mathrm{n}=981)\end{array}$ & $\begin{array}{c}\text { Group B } \\
(\mathrm{n}=1314)\end{array}$ \\
\hline Personality (1-11) & $38.23 \%$ & $59.51 \%$ \\
Process $(12-16)$ & $37.00 \%$ & $11.80 \%$ \\
Performance (17-21) & $24.77 \%$ & $28.69 \%$ \\
\cline { 2 - 3 } Total Percentages & $100 \%$ & $100 \%$
\end{tabular}

Note: Numbers in parentheses next to each core category indicate the range or portion of the twenty-one defined categories associated with the related core segment (personality, process, or performance).

dence that the professionals may see effectiveness as being more related to the person teaching rather than being a reflection of the content being taught. As Table 4 indicates, a higher number of professionals (over 40 percent) than students placed the greatest weight on the observable characteristics of a teacher (self-confidence, expertise, speaking style, energy, and body language). The importance of these visual cues suggests that live, real-time learning environments (e.g., the traditional classroom, on-site seminars, etc.) might be preferred by professionals over distance learning or web-based instruction in which the teacher is less visible or not seen at all.

The fact that differences exist between the groups (students and professionals) suggests that the development of teaching effectiveness strategies should be audience-specific.

\section{Conclusion}

We came to five conclusions from this study:

1. Group A (dental and medical students and residents) and Group B (dentists and physicians; professionals) appear to have different perceptions as to what classroom teacher qualities they prefer.

2. For Group A students, content design, content organization, and content development were preferred characteristics.

3. Group B professionals strongly favored elements of self-confidence and expertise.

4. Both students and professionals highly valued expertise and speaking style. 
5. These findings can provide guidelines for the development of curriculum and classroom instructional techniques, enhancement of faculty teaching skills, and the design of continuing education programs for practicing professionals.

\section{REFERENCES}

1. Berk RA. Survey of 12 strategies to measure teaching effectiveness. Int J Teaching Learning Higher Educ 2005;17(1):48-62.

2. Howard GS, Conway CG, Maxwell SE. Construct validity of measures of college teaching effectiveness. J Educ Psychol 1985;77(2):187-96.

3. Abrami PC, D'Apollonia S, Cohen PA. Validity of student ratings of instruction: what we know and what we do not. J Educ Psychol 1990;82(2):219-31.

4. Aleamoni LM. Student rating myths versus research facts from 1924 to 1998. J Pers Eval Educ 1999;13(2):153-66.

5. d'Apollonia S, Abrami PC. Navigating student ratings of instruction. Am Psychol 1997;52(11):1198-208.

6. Eiszler CF. College students' evaluations of teaching and grade inflation. Res Higher Educ 2002;43(4):483-501.

7. Emery CR, Kramer TR, Tian RG. Return to academic standards: a critique of student evaluations of teaching effectiveness. Qual Assur Educ 2003;11(1):37-46.

8. Greenwald AG. Validity concerns and usefulness of student ratings of instruction. Am Psychol 1997;52(11):1182-6.

9. Greimel-Fuhrmann B, Geyer A. Students' evaluation of teachers and instructional quality: analysis of relevant factors based on empirical evaluation research. Assess Eval Higher Educ 2003;28(3):229-38.

10. Havelka D, Neal CS, Beasley F. Student evaluation of teaching effectiveness: what criteria are most important. Paper presented at the annual Lilly Conference on College Teaching, Miami University, Oxford, OH, 2003.

11. Lewis KG. Techniques and strategies for interpreting student evaluations. San Francisco: Jossey-Bass, 2001.

12. Millea M, Grimes PW. Grade expectations and student evaluation of teaching. College Student J 2002;36(4): 582-90.

13. Read WJ, Rama DV, Raghunandan K. The relationship between student evaluations of teaching and faculty evaluations. J Educ Bus 2001;76(4):189-92.

14. Shevlin M, Banyard P, Davies M, Griffiths M. The validity of student evaluation of teaching in higher education: love me, love my lectures? Assess Eval Higher Educ 2000;25(4):397-405.

15. Sojka J, Gupta A, Deeter-Schmelz D. Student and faculty perceptions of student evaluations of teaching: a study of similarities and differences. Coll Teach 2002;50(2):44-9.

16. Sproule R. The underdetermination of instructor performance by data from the student evaluation of teaching. Econ Educ Rev 2002;21(3):287-94.

17. Theall M, Abrami PC, Mets LA. The student ratings debate: are they valid? how can we best use them? San Francisco: Jossey-Bass, 2001.

18. Trinkaus J. Students' course and faculty evaluations: an informal look. Psychol Rep 2002;91(3, Pt 1):988.
19. Wachtel HK. Student evaluation of college teaching effectiveness: a brief review. Assess Eval High Educ 1998;23(2):191-212.

20. Cashin WE. Student ratings of teaching: uses and misuses. In: Seldin PA, ed. Changing practices in evaluating teaching: a practical guide to improved faculty performance and promotion/tenure decisions. Bolton, MA: Anker, 1999:25-44.

21. Seldin PA. Self-evaluation: what works? what doesn't? In: Seldin PA, ed. Changing practices in evaluating teaching: a practical guide to improved faculty performance and promotion/tenure decisions. Bolton, MA: Anker Pub. Co., 1999:97-113.

22. Scriven M. The methodology of evaluation: perspectives on curriculum evaluation. Chicago: Rand McNally, 1967.

23. Theall MFJ. Looking for bias in all the wrong places: a search for truth or a witch hunt in student ratings of instruction? New Directions Institutional Res 2001; 25(5):45-56.

24. Sheehan EP, Duprey T. Student evaluations of university teaching. J Instr Psychol 1999;26(3):1-7.

25. Onwuegbuzie AJ, Witcher AE, Collins KMT, Filer JD, Weidmaier CD, Moore CW. Students' perceptions of characteristics of effective college teachers: a validity study of a teaching evaluation form using a mixed-methods analysis. Am Educ Res J 1997;44(1):113.

26. Witcher AE, Onwuegbuzie AJ, Minor LC. Characteristics of effective teachers: perceptions of preservice teachers. Res Schools 2001;8(2):45-57.

27. Schaeffer G, Epting K, Zinn T, Buskist W. Student and faculty perceptions of effective teaching: a successful replication. Teach Psychol 2003;30(2):133-6.

28. Spencer KJ, Schmelkin LP. Student perspectives on teaching and its evaluation. Assess Eval Higher Educ 2002;27(5):397-409.

29. Crumbley L, Henry B, Kratchman S. Students' perceptions of the teaching of college teaching. Qual Assur Educ 2001;9(4):197-207.

30. Okpala CO, Ellis R. The perceptions of college students on teacher quality: a focus on teacher qualifications. Education 2005;126(2):374-83.

31. Kane R, Sandretto S, Heath C. An investigation into excellent tertiary teaching: emphasizing reflective practice. Higher Educ 2004;47(3):283-310.

32. Bryant J, Comisky PW, Crane JS, Zillmann D. Relationship between college teachers' use of humor in the classroom and students' evaluations of their teachers. J Educ Psychol 1980;72(4):511-9.

33. Salles J, Baranauskas MCC, Bigonha RS. Towards a communication model applied to the interface design process. Knowl Base Syst 2001;14(8):455-9.

34. Doutrich D, Hoeskel R, Wykoff L, Thiele J. Teaching teachers to teach with technology. J Cont Educ Nurs 2005;36(1):25-31.

35. Gordon HRD, Yocke R. Relationship between personality characteristics and observable teaching effectiveness of selected beginning career and technical education teachers. J Vocat Tech Educ 1999;16(1):47-66.

36. Hulsmeyer BS, Bowling AK. Evaluating colleagues' classroom teaching effectiveness. Nurse Educ 1986;11(5): 19-23. 
37. Webster J, Hackley P. Teaching effectiveness in technology-mediated distance learning. Acad Manag J 1997;40(6):1282-309.

38. Caso L, Maricchiolo F, Bonaiuto M, Vrij A, Mann S. The impact of deception and suspicion on different hand movements. J Nonverbal Behav 2006;30(1):1-19.

39. Rammstedt B, John OP. Measuring personality in one minute or less: a 10-item short version of the big five inventory in English and German. J Res Pers 2007;41(1):203-12.

40. Ambady N, Rosenthal R. Half a minute: predicting teacher evaluations from thin slices of nonverbal behavior and physical attractiveness. J Pers Soc Psychol 1993;64(3):431-41.

41. Rosip JC, Hall JA. Knowledge of nonverbal cues, gender, and nonverbal decoding accuracy. J Nonverbal Behav 2004;28(4):267-86.

42. Coulson M. Attributing emotion to static body postures: recognition accuracy, confusions, and viewpoint dependence. J Nonverbal Behav 2004;28(2):117-39.

43. Smith HA. Nonverbal communication in teaching. Rev Educ Res 1979;49(4):631-72.

44. Babad E, Avni-Babad D, Rosenthal R. Teachers' brief nonverbal behaviors in defined instructional situations can predict students' evaluations. J Educ Psychol 2003;95(3):553-62.

45. Skiba DJ. Got large lecture hall classes? Use clickers. Nurs Educ Perspect 2006;27(5):278-80.

46. Bok DC. Beyond the ivory tower: social responsibilities of the modern university. Cambridge: Harvard University Press, 1982.

47. Cohen PA. Student ratings of instruction and student achievement: a meta-analysis of multisection validity studies. Rev Educ Res 1981;51(3):281-309.

48. Irby D. Evaluating instructional scholarship in medicine. J Am Podiatr Med Assoc 1993;83(6):332-7.

49. Palchik NS, Burdi AR, Hess GE, Dielman TE. Student assessment of teaching effectiveness in a multi-instructor course for multidisciplinary health professional students. Evaluation Health Professions 1988;11(1):55-73.

50. Knapper C. Broadening our approach to teaching evaluation. New Directions Teach Learn 2001;88:3-9.

51. Lofland J, Lofland LH. Analyzing social settings: a guide to qualitative observation and analysis. 3rd ed. Belmont, CA: Wadsworth Publishing Company, 1995.

52. Bowen GA. Preparing a qualitative research-based dissertation: lessons learned. Qual Rep 2005;10(2):208-22.
53. Creswell JW. Qualitative inquiry and research design: choosing among five traditions. Thousand Oaks, CA: Sage Publications Inc., 1998.

54. Glaser BG. Theoretical sensitivity: advances in the methodology of grounded theory. Mill Valley, CA: Sociology Press, 1978.

55. Byrne MM. Evaluating the findings of qualitative research. AORN J 2001;73(3):703-6.

56. Strauss AL, Corbin JM. Basics of qualitative research: techniques and procedures for developing grounded theory. Newbury Park, CA: Sage Publications Inc., 1998.

57. Scott KW. Relating categories in grounded theory analysis: using a conditional relationship guide and reflective coding matrix. Qual Rep 2004;9(1):112-26.

58. McCaslin ML, Scott KW. Method for studying a human ecology: an adaptation of the grounded theory tradition. The Researcher 2003;17(1):26-32.

59. Boeije H. A purposeful approach to the constant comparative method in the analysis of qualitative interviews. Quality and Quantity 2002;36(4):391-409.

60. Glaser BG, Strauss A. The discovery of grounded theory: strategies for qualitative research. Chicago: Aldine, 1967.

61. Strauss A, Corbin J. Basics of qualitative research: grounded theory procedures and techniques. Newbury Park, CA: Sage Publications, 1990.

62. Dey I. Creating categories: qualitative data analysis. London: Routledge, 1993.

63. Bruner JS, Goodnow JJ, Austin GA. Categories and cognition. In: Spradley JP, ed. Culture and cognition: rules, maps, and plans. New York: Chandler, 1972:168-90.

64. Dye JF, Schatz IM, Rosenberg BA, Coleman ST. Constant comparison method: a kaleidoscope of data. Qual Rep 2000;4(1/2):1-9.

65. Patton MQ. Qualitative evaluation and research methods. 2nd ed. Newbury Park, CA: Sage Publications, 1990.

66. Lincoln YS, Guba EG. Naturalistic inquiry. Beverly Hills, CA: Sage Publications, 1985.

67. Constas MA. Qualitative analysis as a public event: the documentation of category development procedures. Am Educ Res J 1992;29(2):253-66.

68. Golafshani N. Understanding reliability and validity in qualitative research. Qual Rep 2003;8(4):597-607. 